\title{
Variation in purple sea urchin (Strongylocentrotus purpuratus) morphological traits in relation to resource availability
}

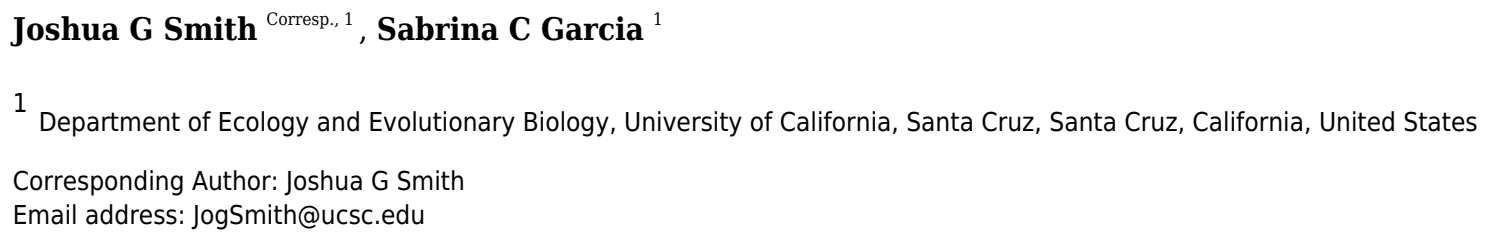

Flexible resource investment is a risk sensitive reproductive strategy where individuals trade resources spent on reproduction for basic metabolic maintenance and survival. This study examined morphological variation in herbivorous sea urchin grazers across a mosaic landscape of macroalgae dominated habitats interspersed with patches of sea urchin barrens to determine whether sea urchins shift energy allocation in response to food limitation. Extensive underwater surveys of habitat attributes (e.g., sea urchin density, algae cover) were paired with detailed laboratory assays (e.g., sea urchin dissections) to determine how resource abundance affects energy allocation between reproductive capacity and body structure in the purple sea urchin, Strongylocentrotus purpuratus. We found that: (1) sea urchins had a more elongate jaw structure relative to body size in habitats void of macroalgae (i.e., barrens), (2) sea urchin reproductive capacity (i.e., gonad index) was lower in barrens and the barrens habitat was primarily comprised of encrusting algae, and (3) sea urchin jaw morphology (i.e., lantern index) and reproductive capacity (i.e., gonad index) were inversely related. These results suggest that sea urchins respond to macroalgae limited environments by shifting energy allocation between reproductive capacity and modifications of the foraging apparatus, which may explain the ability of sea urchins to acquire food in resource-limited environments. 
$6 \quad$ Variation in purple sea urchin (Strongylocentrotus purpuratus) morphological traits in relation to resource availability

*Corresponding author: JogSmith@ucsc.edu; 559-999-0332

Key words: resource allocation, food limitation, growth, echinoidea, morphology, sea urchin 


\section{Abstract}

29 Flexible resource investment is a risk sensitive reproductive strategy where individuals trade resources spent on reproduction for basic metabolic maintenance and survival. This study

31 examined morphological variation in herbivorous sea urchin grazers across a mosaic landscape

32 of macroalgae dominated habitats interspersed with patches of sea urchin barrens to determine

33 whether sea urchins shift energy allocation in response to food limitation. Extensive underwater

34 surveys of habitat attributes (e.g., sea urchin density, algae cover) were paired with detailed

35 laboratory assays (e.g., sea urchin dissections) to determine how resource abundance affects

36 energy allocation between reproductive capacity and body structure in the purple sea urchin,

37 Strongylocentrotus purpuratus. We found that: (1) sea urchins had a more elongate jaw structure

38 relative to body size in habitats void of macroalgae (i.e., barrens), (2) sea urchin reproductive

39 capacity (i.e., gonad index) was lower in barrens and the barrens habitat was primarily comprised

40 of encrusting algae, and (3) sea urchin jaw morphology (i.e., lantern index) and reproductive

41 capacity (i.e., gonad index) were inversely related. These results suggest that sea urchins respond

42 to macroalgae limited environments by shifting energy allocation between reproductive capacity

43 and modifications of the foraging apparatus, which may explain the ability of sea urchins to

44 acquire food in resource-limited environments. 


\section{Introduction}

52 A central issue in life history theory is whether (and how) organisms can be flexible in how

53 they invest resources (Bradshaw 1965, Bårdsen et al. 2011). When faced with food limitations,

54 many organisms will reallocate internal resources, shifting from reproduction and energy storage

55 to basic metabolic maintenance (Braby and Jones 1995, Fiore and Rodman 2001, Bauerfeind and

56 Fischer 2005). This is especially true in dynamic environments where organisms are susceptible

57 to rapid (or even seasonal) changes in resources, or experience periods of extreme climatic

58 events (Boggs and Ross 1993, Lau et al. 2009). Therefore, understanding the spatial and

59 temporal scales over which shifting responses occur can provide insight into when, where, and

60 under what conditions organisms exhibit the plasticity to allocate resources to favor survival, or

61 maintain their reproductive capacity.

62 Sea urchins (Echinoidea) are important benthic herbivores in many marine systems because

63 of their ability to fundamentally transform macroalgal-dominated communities to 'barrens' void

64 of macroalgae (Filbee-Dexter and Scheibling 2014). The ability for sea urchins to reallocate

65 resources may be one explanation for the persistence of dense aggregations of sea urchins in

66 barren habitats with little food availability (Simenstad et al. 1978, McShane and Anderson 1997).

67 Several studies have documented variation in sea urchin jaw structure and body shape as a result

68 of changes in food availability (Ebert 1980, Black et al. 1982 and 1984, Levitan 1989, Levitan

69 1991). Food stress can also negatively impact reproductive success. Sea urchin gonads are both

70 reproductive organs and important energy reserves that serve as a proxy for measuring overall

71 health (Walker 1981, Lawrence and Lane 1982, Rogers-Bennett et al. 1995). Gonadal condition

72 has been found to decrease over extended periods of food limitation as sea urchins are forced to

73 expend energy reserves as food supplements (Vadas 1977, Andrew 1989, James 2007, Schroeter 
74 et al. 2009). While these studies suggest that sea urchins possess a high degree of phenotypic

75 plasticity (i.e., overall test size and jaw structure), the spatio-temporal scale over which

76 population-level morphological responses occur is less understood and may only be revealed by

77 tracking population responses through significant environmental changes, such as modifications

78 in the abundance of macroalgae.

79 Along the central coast of California, active grazing by purple sea urchins (Strongylocentrotus

80 purpuratus) shifted expansive kelp forests into a patchy mosaic of remnant kelp forests

81 interspersed with sea urchin barrens (Smith et al. 2021). Beginning in the year 2014, an outbreak

82 of purple sea urchins initiated kelp deforestation, which provided a unique and timely

83 opportunity to explore sea urchin phenotypic plasticity in a recently transitioned system. Kelp

84 forests and sea urchin barrens represent two important grazing environments. In patches of kelp

85 forests, sea urchins are often at low densities and primarily employ a risk-averse passive-grazing

86 strategy on detrital (hereafter, 'drift') kelp (Filbee-Dexter and Scheibling 2014). However, in sea

87 urchin barrens where drift is limited, sea urchins alter their behavior, emerge from the refuge

88 space of crevices, and actively graze at high densities on nutrient-poor encrusting algae species

89 (Harrold and Pearse 1987, Steneck et al. 2002, DeVries et al. 2019). Therefore, the success and

90 survival of sea urchins in these two distinct habitats may be strongly dependent on the ability of

91 sea urchins to modify resource allocation from reproduction (i.e., gonad development) to

92 survival (i.e., metabolic maintenance).

93 Using the mosaic landscape of kelp forests and sea urchin barrens that initiated just three

94 years prior to this study, we examined morphological variation in three fundamental sea urchin

95 traits: jaw shape, body shape, and gonad condition. Specifically, we tested the following

96 hypotheses: (1) sea urchin jaw (hereafter, Aristotle's 'lantern') morphology varies as a function 
97 of habitat type (i.e., kelp forest, sea urchin barren), (2) differences in observed lantern

98 morphology between habitat types is a function of the algal assemblage in each of those habitats,

99 and (3) sea urchin reproductive capacity (i.e., gonadal condition) is inversely related to lantern

100 morphology, indicating resource trade-offs between reproduction and metabolic maintenance.

101

102 Methods

103 We combine spatially explicit observations of habitat attributes (algae cover, sea urchin

104 density) between kelp forests and sea urchin barrens with detailed measurements of

105 morphological traits (jaw shape, body shape, gonad condition) of sea urchins collected from the

106 field to determine the consequences of resource variation on sea urchin morphology.

107

108 Survey design

109 This study was conducted along the southern end of Monterey Bay, California, USA. In 2014,

110 overgrazing by purple sea urchins shifted a once expansive kelp forest landscape to a patchy

111 mosaic of remnant forests interspersed with sea urchin barrens (Smith et al. 2021). While this

112 study was conducted just three years after the initiation of the urchin outbreak, the spatial extent

113 of barren patches continued to expand both during and for several years following this study.

114 Underwater surveys were conducted from June to September in 2017. A total of 83 randomly

115 assigned subtidal survey sites within the study region were sampled to evaluate sea urchin size

116 structure and density, habitat type (i.e., barrens, kelp forests), and algae cover (Figure 1). Survey

117 sites were located between the Breakwater (36.61237578 N, 121.8947703 W) and Point Pinos

118 (36.63878914 N, 121.9246315 W) in Monterey, CA, in 5 to 20 meters of water on rocky reef

119 substratum. Each site was categorically assigned in situ as one of two habitat types: kelp forest 
120 (characterized by high macroalgae presence and low sea urchin density), or sea urchin barren

121 (characterized by low macroalgae presence, dominated by coralline algae, and with high sea

122 urchin density). These two categories formed the basis for all categorical comparisons and

123 analyses.

124 Each site was surveyed using a radial sampling design following the methods described in

125 Smith et al. 2021. Briefly, a total of eight 5-m long transects were surveyed at each site, radiating

126 from a fixed central position. A single transect was assigned to each cardinal (N, S, E, W) and

127 inter-cardinal (NE, NW, SE, SW) direction around the survey site. Two randomly placed $1 \mathrm{~m} \mathrm{x}$

$1281 \mathrm{~m}$ photographic quadrats were sampled per transect (16 total quadrats per site). The location of

129 the quadrats along the transects were assigned using a randomly stratified design so that the

130 quadrats were not intentionally biased towards either the center or outer edge of the site. Within

131 each quadrat, the total number of sea urchins were quantified by searching in crevices and

132 carefully examining dense algae. By utilizing the same sampling design at each site, each of our

13383 survey sites represent a replicate sample.

135 Variation in sea urchin morphology between habitats

136 To test the hypothesis that lantern morphology and body shape varies as a function of habitat

137 type, we conducted a series of laboratory dissections with sea urchins collected from spatially

138 referenced field survey sites (study animal collection approved by the California Department of

139 Fish and Wildlife, permit no. SC-389). Two sea urchins were randomly collected from fixed

140 opposite corners of each quadrat for a maximum of 32 sea urchins per site. Only urchins greater

141 than $3 \mathrm{~cm}$ were collected for dissections. These size classes of urchins are too large to have 
142 settled from the plankton later than 2014. Therefore, most of the dissected urchins were likely

143 present during the 2014 habitat transformation event.

144 A total of 1,058 purple sea urchins were collected for this study. Upon collection, sea urchins

145 were immediately 'fixed' following the methods of Harrold and Reed (1985) to preserve gonads

146 for dissection. Sea urchins were injected with $3-15 \mathrm{~mL}$ of $10 \%$ neutral-buffered formalin

147 (depending on animal size) through the peristomal membrane. After a 24-hour fixation period,

148 sea urchin tests were measured to the nearest $0.5 \mathrm{~mm}$ using Vernier calipers. Test diameter was

149 recorded as the maximum distance across the test, excluding spines, and test height was

150 measured as the length between the oral and aboral surfaces (to the nearest $0.05 \mathrm{~mm}$ ). After these

151 measurements were obtained, sea urchins were dissected for gonads and to measure lantern

152 morphology. Our measure of lantern length was recorded as the distance from the oral tip to the

153 aboral surface of the epiphysis. Lantern width was measured as the maximum diameter of the

154 aboral epiphysis surface.

155 We evaluated both sea urchin lantern length and gonad weight as independent functions of

156 test diameter between habitat types (barrens, forest) using separate analysis of covariance

157 (ANCOVA) tests. In both models, we tested the homogeneity of slopes assumption by evaluating

158 the effect of test diameter, habitat type (barren, forest), and their interaction. We found that the

159 interaction was not significant, therefore we ran reduced two-term ANCOVAs with test diameter

160 and habitat type as independent model terms.

161 Sea urchin gonad weight serves as a useful metric for assessing animal health and reproductive 162 capacity (Walker 1981, Lawrence and Lane 1982). To account for the relationship between

163 urchin size and gonad weight, we used a gonad index to comparatively evaluate sea urchin gonad

164 condition and lantern morphology. Sea urchin gonads were removed from each individual, 
165 blotted dry, and wet-weighed to the nearest $0.001 \mathrm{~g}$. Gonad index was calculated as the percent

166 body mass comprised of gonads:

167

168

Eq. 1 Gonad Index $(G I)=\frac{\text { Gonad Wet Weight }(g)}{(\text { Total Wet Weight }(g))} X 100$

169 Therefore, higher GI values indicate greater gonad mass relative to the animal's total body mass.

170

Relationship between sea urchin morphology and algae cover

172 Photographic quadrats were used to estimate algae cover in order to test for a relationship

173 between algae cover, sea urchin morphology, and condition. Within each quadrat, still imagery

174 was collected using a downward facing GoPro Hero4 camera and two LED Sola video lights.

175 Still photos of each quadrat were analyzed in ImageJ using 16 uniform-points per quadrat.

176 Photos were analyzed in the lab where an observer recorded the organism below each point to

177 the lowest taxonomic level possible. However, because many species of algae are difficult to

178 taxonomically identify from photo imagery, algae were organized into the following

179 morphological groups: brown algae (predominately Macrocystis pyrifera), foliose red algae

180 (predominately Chondracanthus spp), and encrusting algae (includes encrusting red and

181 encrusting coralline algae). These morphological groups were selected based on their known

182 status as indicators for kelp forests (brown algae, foliose red) or sea urchin barren (encrusting

183 algae) habitats (Filbee-Dexter and Scheibling 2014). First, we used a series of linear regressions

184 to test for associations between the cover of algae and two metrics of sea urchin morphology

185 (lantern index, gonad index). Because lantern length was directly proportional to test diameter in

186 both habitats, we used a lantern index to account for length-size relationships (e.g., larger

187 animals have larger lanterns), defined as:

Peer) reviewing PDF | (2020:09:53108:3:0:NEW 29 Mar 2021) 
189 Therefore, higher LI values indicate a longer jaw length relative to body size. We then used a

190 beta regression on the pooled quadrat data for each site to account for the proportional (0-1)

191 response variable (Ferrari and Cribari-Neto 2004), with mean sea urchin density as a continuous

192 predictor. We examined sea urchin body size as the ratio of test diameter to test height between

193 habitat types and found no significant difference. Additionally, lantern width was relatively

194 proportional to body size.

\section{Results}

197 Variation in sea urchin morphometrics as a function of habitat

198 Sea urchin density was greater in barrens $\left(M=13.79 \pm 1.42\right.$ S.E. individuals $\left./ \mathrm{m}^{2}\right)$ than in the 199 kelp forest habitat $\left(\mathrm{M}=5.33 \pm 0.69\right.$ S.E. individuals $\left./ \mathrm{m}^{2}, \mathrm{P}<0.0001\right)$. Although there were 200 differences in sea urchin density between habitat types, the mean test diameter for sea urchins 201 from barrens $(M=36.58 \pm 0.51$ S.E. $\mathrm{mm})$ and kelp forests $(\mathrm{M}=37.07 \pm 0.62 \mathrm{~S} . \mathrm{E} . \mathrm{mm})$ was not 202 significantly different. Similarly, the relationships between lantern length and lantern width, and 203 between test diameter and test height, did not vary with habitat type (Figure 2).

204 An analysis of covariance (ANCOVA) revealed that relative lantern length was significantly 205 greater in sea urchin barrens than in kelp forest habitats $(\mathrm{F}=72.63, \mathrm{DF}=2$ and $80, \mathrm{P}<0.0001)$. 206 This difference in lantern length was most pronounced in individuals less than $49 \mathrm{~mm}$ (Figure 3 207 A). Although lantern length appeared to broadly converge between habitat types in individuals 208 greater than $50 \mathrm{~mm}$, the interaction between habitat type and test diameter was not significant. 209 Conversely, gonad weight was significantly higher in the kelp forest habitat than in sea urchin 210 barrens $(\mathrm{F}=76.54, \mathrm{DF}=2$ and $80, \mathrm{P}<0.0001$; Figure $3 \mathrm{~B})$. 
211 The percent cover of algae was correlated with both lantern index and gonad index (Figure 4).

212 There was a positive and linear relationship between encrusting algae and lantern index $\left(\mathrm{R}^{2}=\right.$

$2130.33, \mathrm{P}<0.001$; Figure 4a), while brown $\left(\mathrm{R}^{2}=0.14, \mathrm{P}<0.001\right.$; Figure $\left.4 \mathrm{c}\right)$ and foliose red $\left(\mathrm{R}^{2}=\right.$

$2140.14, \mathrm{P}<0.001$; Figure 4E) algae were negatively correlated with lantern index. In general, these

215 lantern index relationships were inversely correlated with gonad index. Cover of encrusting algae

216 was negatively correlated with gonad index $\left(\mathrm{R}^{2}=0.4, \mathrm{P}<0.001\right.$; Figure $\left.4 \mathrm{~B}\right)$, while brown $\left(\mathrm{R}^{2}=\right.$

217 0.075, $\mathrm{P}<0.02$; Figure 4D) and foliose red $\left(\mathrm{R}^{2}=0.35, \mathrm{P}<0.001\right.$; Figure 4F) algae were

218 positively correlated.

219

220

Habitat attributes of kelp forest and sea urchin barrens

221 We explored differences in the cover of key habitat-indicating algae groups (brown algae,

222 foliose red, and encrusting algae) and sea urchin density between habitat types to determine

223 factors that may influence variation in sea urchin morphological traits. A reduced two-term

224 model with brown algae and red foliose algae explained the most variation in habitat type (AIC = $22561.48, \mathrm{DF}=3, \mathrm{P}<0.0001)$. Based on the model coefficients, high cover of brown and foliose 226 algae explained a greater likelihood of a forest habitat, while the cover of encrusting algae was 227 negatively correlated with the forest habitat. Because of the linear relationship between lantern 228 index and sea urchin density, identical relationships were found between percent cover of algae 229 and sea urchin density. Finally, there was a positive relationship between encrusting algae and 230 sea urchin density $(\mathrm{F}=36.54, \mathrm{P}<0.0001)$, while both the cover of brown $(\mathrm{F}=12.47, \mathrm{P}=$

$2310.0007)$ and foliose red $(\mathrm{F}=14.02, \mathrm{P}<0.0003)$ were negatively correlated with sea urchin 232 density (Figure 5). 


\section{Discussion}

235 This study examined variation in sea urchin morphological traits (lantern shape, body shape,

236 gonad condition) across a patchy mosaic landscape of kelp forests interspersed with resource-

237 limited sea urchin barrens. The inverse relationship between reproductive capacity (i.e., gonad

238 index) and jaw morphology (i.e., lantern length) suggests that when food is scarce, lanterns are

239 lengthened and gonad production declines. The cover of brown and foliose red algae was

240 correlated with habitat type, which reinforces that key algal groups facilitate morphometric

241 variation in sea urchins. Our findings reveal that sea urchins can alter the Aristotle's lantern to

242 persist in dense aggregations and in low resource environments.

243 The sea urchin barrens that initiated three-years prior to our study created a unique

244 opportunity to explore variation in sea urchin morphology between barrens and macroalgae

245 dominated habitats. This recently transitioned system comprised of a mosaic of kelp forests and

246 sea urchin barrens helped to reveal that sea urchins may develop an enlarged feeding apparatus

247 relative to body shape and size over a relatively short duration. This suggests that lantern

248 morphology is likely influenced by the composition and abundance of macroalgae. Foliose red

249 and brown algae are common within patches of kelp forest, while barrens are primarily

250 dominated by encrusting coralline and encrusting red algae (Simenstad 1978, Filbee-Dexter and

251 Scheibling 2014). One possible explanation for lengthened sea urchin lanterns in barrens is

252 increased foraging ability, where a longer and more supported feeding apparatus enhances

253 scraping efficiency for encrusting algae species that dominate sea urchin barrens. In our

254 laboratory dissections, sea urchins with longer lanterns appeared to consume larger amounts of

255 encrusting algae scraped from rocks than those with smaller lanterns. An increased ability to 
256 scrape food off rocks supports the positive relationship found in our study between encrusting

257 algae and lantern index.

258 In addition to food limitation driving sea urchin lantern structure, sea urchins have also been

259 shown to elicit similar morphological changes in response to differences in sea urchin density

260 (Levitan 1989). Our study found a linear relationship between lantern index and sea urchin

261 density, which is similar to that reported by Black (1982) in Rottnest Island, Western Australia

262 with Echinometra mathaei having longer lanterns in areas of higher densities. Other field

263 experiments have produced evidence for density dependent test growth and shrinkage (Ebert

264 1967, Pearse and Pearse 1975). Collectively, these studies highlight the dynamic nature of

265 external factors that impact sea urchin morphology.

266 Gonad index is a metric often used to assess reproductive capacity, general health, and energy

267 storage in sea urchins (Walker 1981, Lawrence and Lane 1982, Ebert et al. 2012, James and

268 Siikavuopio 2012). In this study, gonad index was found to be greatest in forests and lowest in

269 barrens, consistent with existing evidence that gonadal condition can be affected by the quantity

270 and quality of available food (Lau et al. 2009). Sea urchins may also allocate energy based on

271 their reproductive stage. For example, Guillou et al. (2000) found that adult Sphaerechinus

272 granularis fed in the pre-spawning stage only carried out gonadal growth and did not expend any

273 resources to body growth, suggesting a seasonal energy trade off. This conversion has been

274 found to happen within as short of a span as 3 weeks, suggesting that this rapid shift from

275 gonadal development and nutrient storage to body maintenance is beneficial in a habitat rapidly

276 transformed from food abundant to food limited (Russell 1998).

277 This study explored variation in sea urchin morphometrics in response to the onset of

278 widespread sea urchin barrens in Monterey Bay, California, USA. Our study reveals that sea 
279 urchins alter the structure of their foraging apparatus, Aristotle's lantern, and energy storage

280 organs (gonads) without fundamental changes in body shape, and these changes may occur over

281 a relatively short duration. This plastic morphological response to variation in food availability

282 provides support that lengthened sea urchin lanterns may enhance grazing efficiency and success

283 in food limited environments. Ultimately, these results highlight the ability for important kelp

284 forest grazers such as sea urchins to persist in habitats that are void of macroalgae for extended 285 periods of resource limitation.

286

287 Acknowledgements

288 We deeply thank T. Gorra and dozens of volunteers who contributed to fieldwork and laboratory 289 dissections. We also thank R. Mehta for initial feedback and the two reviewers whose comments 290 substantially improved the manuscript. Funding for this project was provided by the National

291 Science Foundation (NSF) Graduate Research Fellowship to JGS, the Future Leaders in Coastal

292 Science Award to JGS and SCG, and by NSF Grant OCE-1538582.

293

294 Competing interests

295 The authors declare no competing interests.

297 Data availability

298 Datasets and analysis code used in this study are available on Dryad

299 (https://doi.org/10.7291/D11M38)

300

301 


\section{Literature Cited}

303 Andrew, N. L. 1989. Contrasting ecological implications of food limitation in sea urchins and herbivorous gastropods. Marine Ecology Progress Series. 51 (1-2): 189-193.

305

306

307

308

309

310 327

Bårdsen, B. J., Henden, J. A., Fauchald, P., Tveraa, T., and Stien, A. 2011. Plastic reproductive allocation as a buffer against environmental stochasticity-linking life history and population dynamics to climate. Oikos. 120(2): 245-257.

Bauerfeind, S. S. and Fischer, K. 2005. Effects of food stress and density in different life stages on reproduction in a butterfly. Oikos. 111(3): 514-524.

Black, R., Johnson, M. S. and Trendall, J. T. 1982. Relative size of Aristotle's lantern in Echinometra mathaei occuring at different densities. Marine Biology. 71: 101-106.

Black, R., Codd, C., Hebbert, D., Vink, S. and Burt, J. 1984. The functional significance of the relative size of Aristotle's lantern in the sea urchin Echinometra mathaei (de Blainville). Journal of Experimental Marine Biology and Ecology. 77 (1-2): 81-97.

Boggs, C. L. and Ross, C. L. 1993. The effect of adult food limitation on life history traits in Speyeria mormonia (Lepidoptera: Nymphalidae). Ecology. 74 (2): 433-441.

Braby, M. F. and Jones, R. E. 1995. Reproductive patterns and resource allocation in tropical butterflies: influence of adult diet and seasonal phenotype on fecundity, longevity and egg size. Oikos. 72 (2): 189-204.

Bradshaw, A. D. 1965. The evolutionary significance of phenotypic plasticity in plants. Advances in Genetics. 13: 115-155.

DeVries, M. S., Webb, S. and Taylor, J. R. A. 2019. Re-examination of the effects of food abundance on jaw plasticity in purple sea urchins. Marine Biology. 166 (11): 141.

Ebert, T. A. 1967. Growth and repair of spines in the sea urchin Strongylocentrotus purpuratus 
328

329

330

331

332

333

334

335

336

337

338

339

340

341

342

343

344

345

346

347

348

349

350

351

(Stimpson). The Biological Bulletin, 133(1), 141-149.

Ebert, T. A. 1980. Relative growth of sea urchin jaws: an example of plastic resource allocation. Bulletin of Marine Science. 30(2): 467-474.

Ebert, T. A., Hernández, J. C., and Russell, M. P. 2012. Ocean conditions and bottom-up modifications of gonad development in the sea urchin Strongylocentrotus purpuratus over space and time. Marine Ecology Progress Series. 467: 147-166.

Ferrari, S. L. P., and Cribari-Neto, F. 2004. Beta regression for modelling rates and proportions. Journal of Applied Statistics. 31(7): 799-815.

Filbee-Dexter, K. and Scheibling, R. E. 2014. Sea urchin barrens as alternative stable states of collapsed kelp ecosystems. Marine Ecology Progress Series. 495: 1-25.

Fiore, A. D. and Rodman, P. S. 2001. Time Allocation Patterns of Lowland Woolly Monkeys (Lagothrix lagotricha poeppigii) in a Neotropical Terra Firma Forest. International Journal of Primatology. 22(3): 449-480.

Guillou, M., Lumingas, L. J., Michel, C. 2000. The effect of feeding or starvation on resource allocation to body components during the reproductive cycle of the sea urchin Sphaerechinus granularis (Lamarck). Journal of Experimental Biology. 245(2): 183-196.

Harrold, C. and Reed, D. C. 1985. Food availability, sea urchin grazing, and kelp forest community structure. Ecology. 66(4): 1160-1169.

Harrold, C. and Pearse, J. 1987. The Ecological role of echinoderms in kelp forests. Echinoderm Studies. 2: 137-233.

James, P. 2007. The effects of environmental factors and husbandry techniques on roe enhancement of the New Zealand sea urchin, Evechinus chloroticus. Doctoral Thesis. Victoria University of Wellington. 
352 James, P. and Siikavuopio, S. A. 2012. Guide to the sea urchin reproductive cycle and staging 353 sea urchin gonad samples. Nofima, Troms. p. 23.

354 Lau, D. C. C., Lau, S. C. K., Qian, P. Y., Giu, J. W. . 2009. Morphological plasticity and

355

356

357

358

359

360

361

362

363

364

365

366

367

368

369

370

371

372

373

374

375

376 resource allocation in response to food limitation and hyposalinity in a sea urchin. Journal of Shellfish Research. 28(2): 383-388

Lawrence, J.M and Lane, J. M. 1982. The utilization of nutrients by post-metamorphic echinoderms. Echinoderm Nutrition. 1: 331-371.

Levitan, D. R. 1989. Density-dependent size regulation in Diadema antillarum: effects on fecundity and survivorship. Ecology. 70(5): 1414-1424.

Levitan, D. R. 1991. Skeletal chances in the test and jaws of the sea urchin Diadema antillarum in response to food limitation. Marine Biology. 111 (3): 431-435.

McShane, P. E. and Anderson, O. F. 1997. Resource allocation and growth rates in the sea urchin Evechinus chloroticus (Echinoidea: Echinometridae). Marine Biology. 128: 657-663.

Pearse, J. S., and Pearse, V. B. 1975. Growth zones in the echinoid skeleton. American Zoologist, 15(3): 731-751.

Rogers-Bennett, L., Bennett, W. A., Fastenau, H. C., and Dewees, C. M. 1995. Spatial variation in red sea urchin reproduction and morphology: implications for harvest refugia. Ecological Applications. 5:1171-1180.

Russell, M. P. 1998. Resource allocation plasticity in sea urchins: rapid, diet induced, phenotypic changes in the green sea urchin, Strongylocentrotus droebachiensis (Müller). Journal of Experimental Biology and Ecology. 220(1): 1-14.

Schroeter, S. C., Gutiérrez, N. L., Robinson, M., Hilborn, R., and Halmay, P. 2009. Moving from data poor to data rich: a case study of community-based data collection for the San Diego 
red sea urchin fishery. Marine and Coastal Fisheries: Dynamics, Management, and Ecosystem Science. 1(1): 230-243.

379 Simenstad, C. A., Estes, J. A., Kenyon, K. W. 1978. Aleuts, sea otters, and alternate stable-state $380 \quad$ communities. Science. 200(4340): 403-411.

381 Smith, J. G., Tomoleoni, J., Staedler, M, Lyon, S., Fujii, J., and Tinker, T. 2021. Behavioral 382 responses across a mosaic of ecosystem states restructure a sea otter-urchin trophic cascade. Proceedings of the National Academy of Sciences. 118(11). DOI: https://doi.org/10.1073/pnas.2012493118

385

386

387

388

389

390

391

392

393

394

395

396

397

398

399

\section{2}

393

Steneck, R. S., Graham, M. H., Bourque, B. J., Corbett, D., Erlandson, J. M., Estes, J. A. and Tegner, M. J. 2002. Kelp forest ecosystems: biodiversity, stability, resilience and future. Environmental Conservation. 29(4): 436-459.

Vadas, R. L. 1977. Preferential feeding: An optimization strategy in sea urchins. Ecological Monographs. 47(4): 337-371.

Walker, M. M. 1981. Influence of season on growth on the sea urchin Evechinus chloroticus. New Zealand Journal of Marine and Freshwater Research. 15(2): 201-205. 
400

401

402

403

404

405

406

407

408

409

410

411

412

413

414 Figure 4. Lantern index (left column) and gonad index (right column) as a function of the

415 percent cover of encrusting (A, B), brown (C, D), and foliose red (E, F) algae. Each point depicts

416

417 surrounding each linear regression line.

418

419 Figure 5. Beta regression probability density functions for proportion of algae cover as a

420 function of mean purple urchin density. 
Figure 1

Subtidal survey sites along the Monterey Peninsula, California, USA.

Brown squares indicate kelp forests and purple triangles indicate sea urchin barrens.

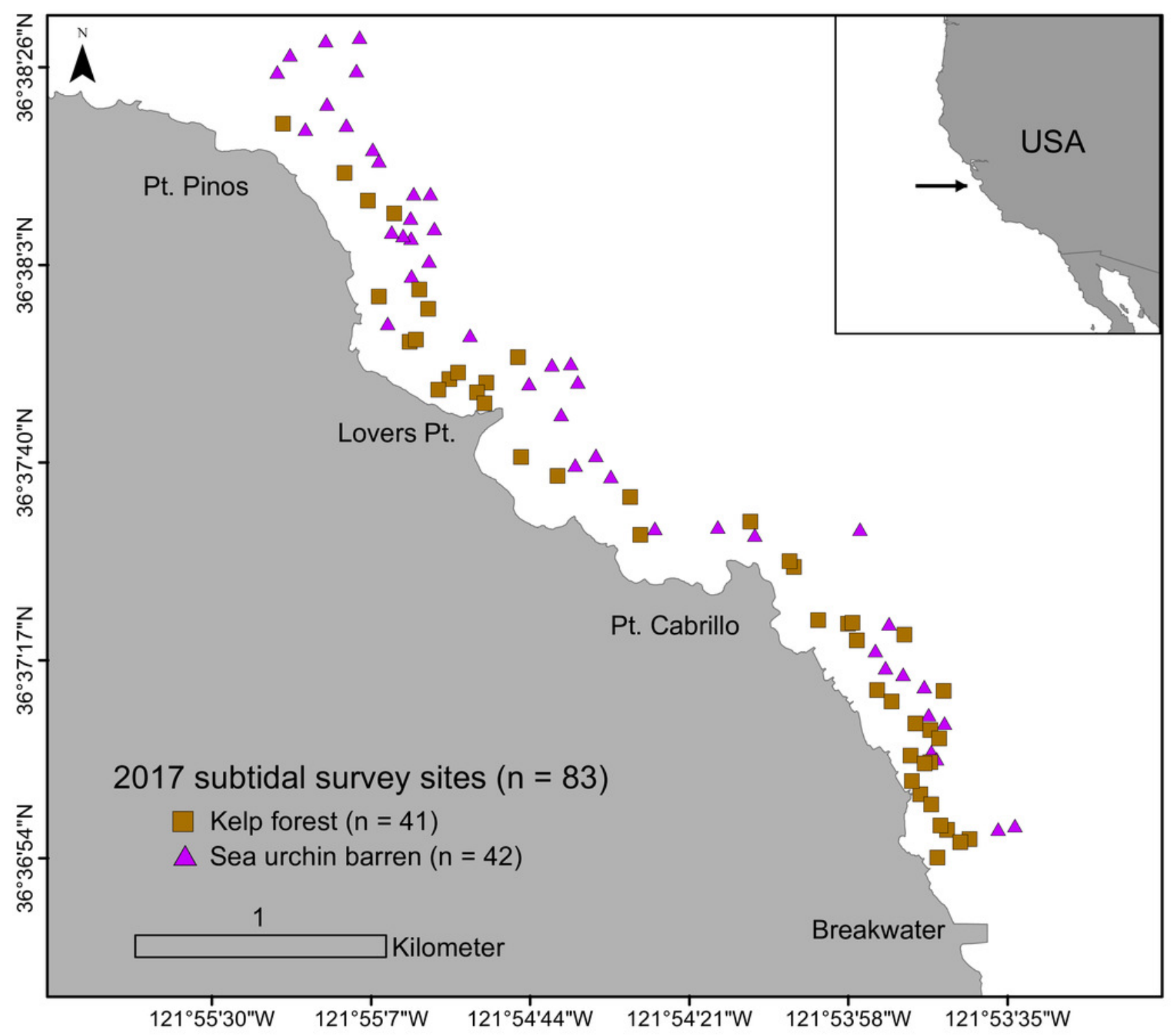


Figure 2

Sea urchin shape and structure.

Sea urchin shape and body structure with $(A)$ lantern length $(\mathrm{mm})$ plotted against lantern width $(\mathrm{mm})$, and $(B)$ test height $(\mathrm{mm})$ plotted against test diameter $(\mathrm{mm})$. Linear regressions lines are shown for barrens (purple) and forests (green) and shaded with the $95 \%$ confidence intervals surrounding each mean.
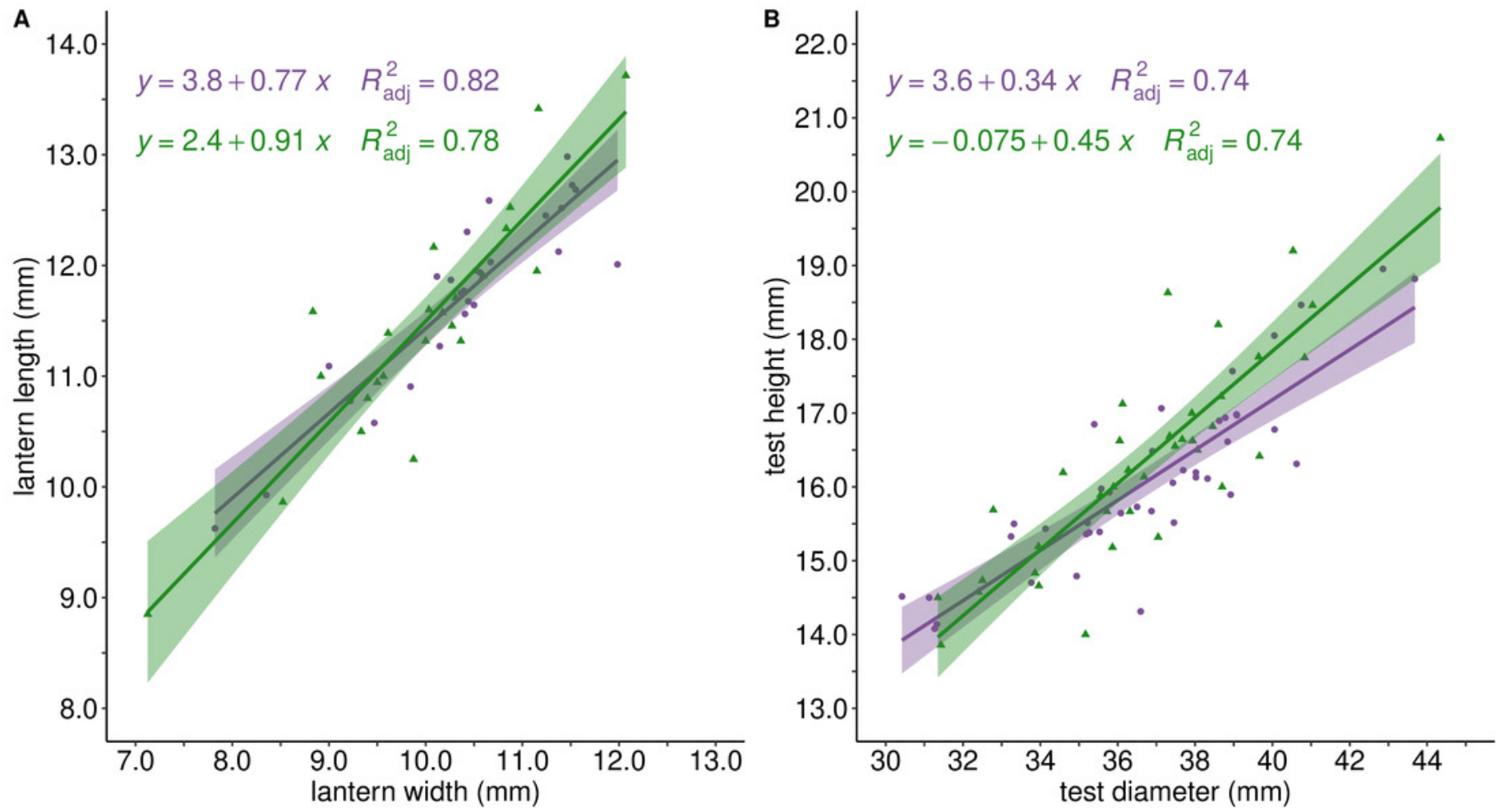
Figure 3

Lantern length and gonad weight between habitat types.

Log-transformed lantern length (A) and gonad weight (B) between kelp forests (green) and sea urchin barrens (purple) with log-transformed test diameter as a covariate. Shaded regions depict the $95 \%$ confidence of fit surrounding each regression line.
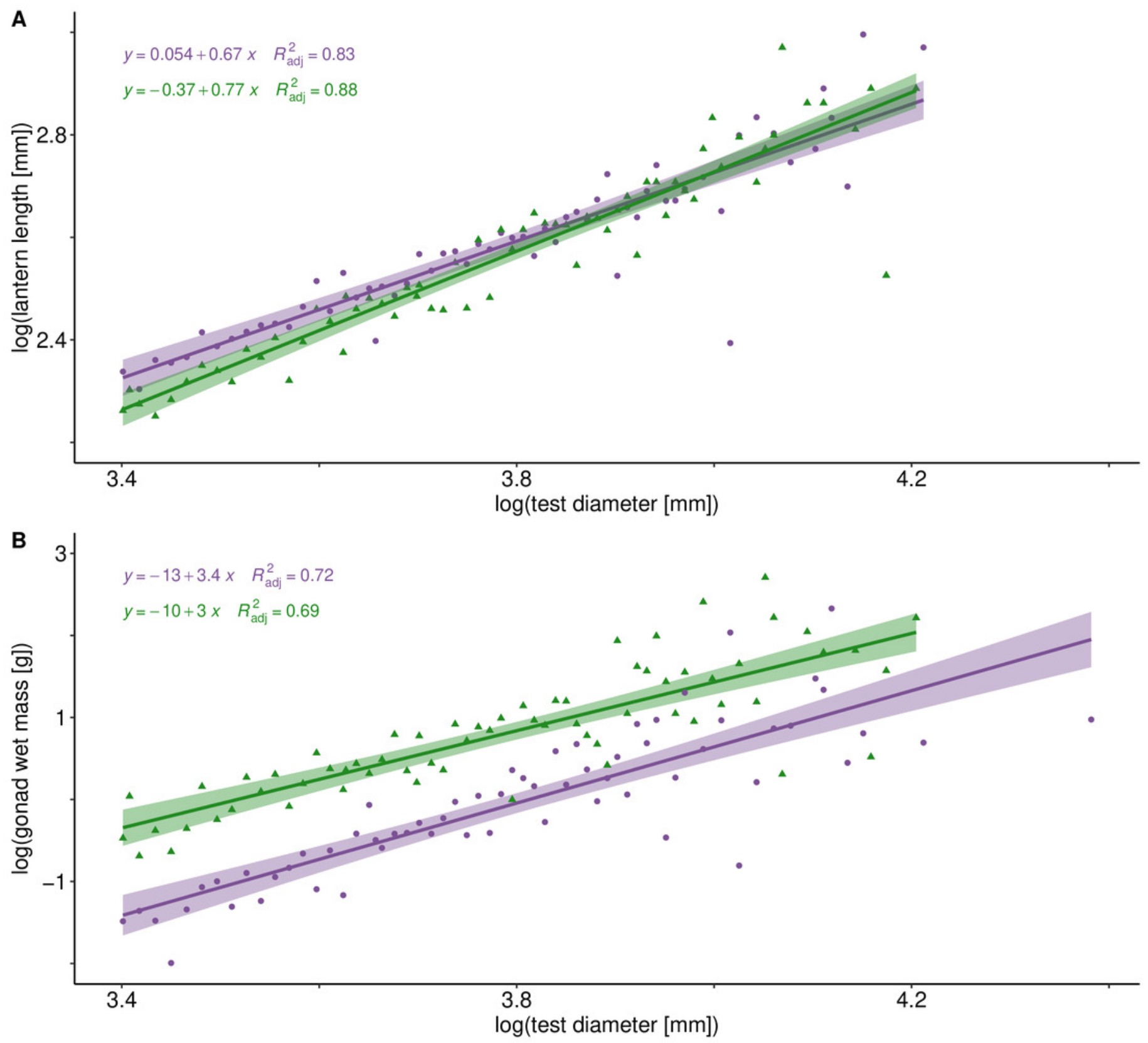


\section{Figure 4}

Lantern index and gonad index as functions of the percent cover of algae.

Lantern index (left column) and gonad index (right column) as a function of the percent cover of encrusting ( $A, B)$, brown $(C, D)$, and foliose red $(E, F)$ algae. Each point depicts the mean cover of algae within a given site. Shaded regions indicate the $95 \%$ confidence of fit surrounding each linear regression line. 

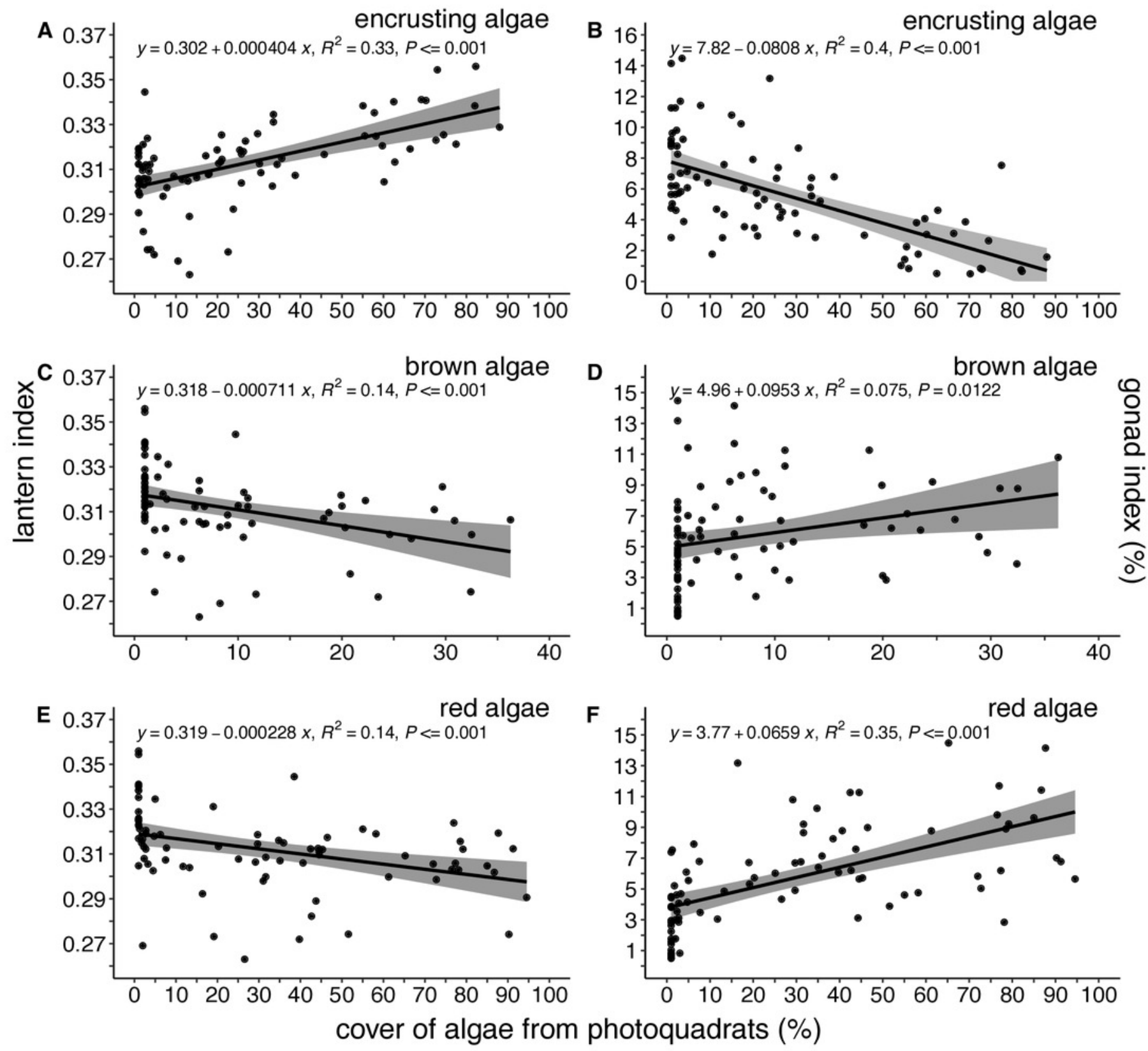
Figure 5

Beta regression probability density functions for proportion of algae cover as a function of mean purple urchin density.

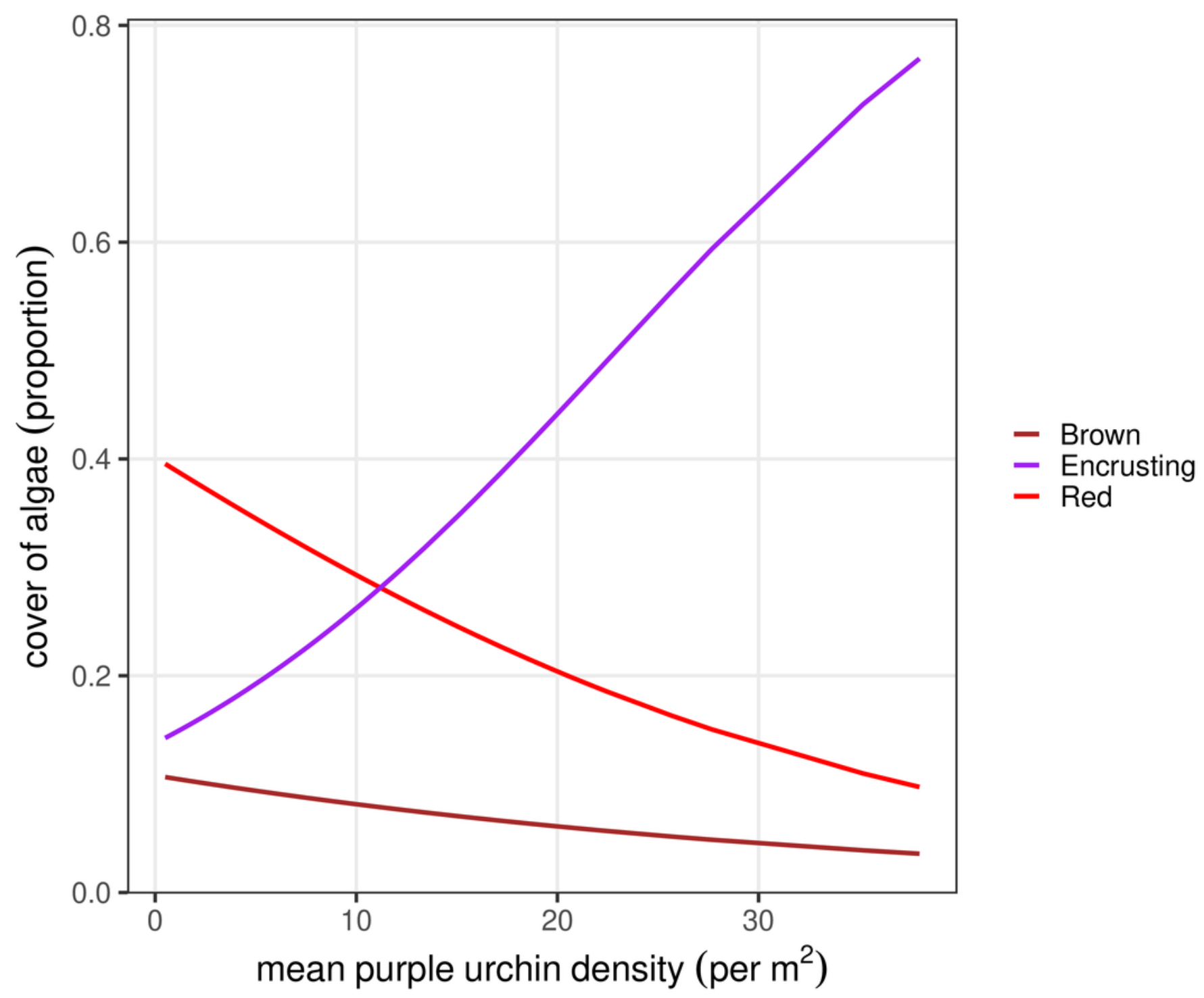

